\title{
An unusual case of refractory wheeze
}

\author{
Venkat Ramesh, ${ }^{1}$ Vishak Acharya, ${ }^{2}$ Narasimha Pai, ${ }^{3}$ Ananda Krishnan ${ }^{4}$
}

${ }^{1}$ Internal Medicine, Kasturba Medical College, Mangalore, Karnataka, India

${ }^{2}$ Kasturba Medical College, Manipal University, Mangalore, Karnataka, India ${ }^{3}$ Department of Cardiology, Kasturba Medical College, Manipal University, Mangalore, Karnataka, India

${ }^{4}$ Saba Hospital, Kannur, Kerala, India

\section{Correspondence to} Dr Venkat Ramesh, venkatramesh.ramesh@gmail. com

Accepted 29 January 2015

CrossMark

To cite: Ramesh $\mathrm{V}$, Acharya $\mathrm{V}$, Pai N, et al. BMJ Case Rep Published online: [please include Day Month Year] doi:10.1136/bcr-2014206963

\section{SUMMARY}

A 37-year-old man presented with a history of episodic wheeze and breathlessness of 3 years' duration refractory to treatment. Physical examination revealed diffuse expiratory polyphonic rhonchi while the remainder of the examination including the cardiac examination was reported as normal. Pulmonary function testing revealed mild obstruction with bronchodilator reversibility. The patient was discharged on a 6-month course of antitubercular treatment (ATT) as bronchial brush cytology (obtained via bronchoscopy) was positive for acid-fast bacilli. The patient presented after completing 6 months of ATT with persistent symptoms, a loud S1 and a mid-diastolic murmur at the apex. High-resolution $\mathrm{CT}$ of the chest showed bilateral dependent ground glass opacities. An echocardiogram revealed a left atrial myxoma, and normal RV size and pressures. The patient underwent successful surgical removal of the same, and made a complete recovery. Refractory wheeze is a very unusual presentation of a left atrial myxoma.

\section{BACKGROUND}

In making the diagnosis of refractory asthma, it is important to consider and exclude other diseases in the differential diagnosis of wheeze, dyspnoea, cough and eosinophilia. ${ }^{1}$ The diagnostic work up of patients suspected of having chronic refractory asthma should consist of full pulmonary function tests including spirometry with a flow-volume curve, total lung capacity, residual volume and diffusion capacity, as well as daily peak flow monitoring. ${ }^{2}$ Additional suggested clinical tests include serum IgE and measuring eosinophil levels. ${ }^{13}$ It is also important to consider non-pulmonary causes including systemic and cardiovascular causes while evaluating a refractory asthmatic.

We report a case of refractory wheeze that was initially treated, unsuccessfully, as asthma. The patient also has coexisting pulmonary tuberculosis, which was successfully treated. However, a complete evaluation revealed a large left atrial myxoma with a normal right heart to be the cause for refractory wheeze. In retrospect, cardiac examination in the initial assessment was overshadowed by the positive auscultatory findings in the lungs. Refractory wheeze is not synonymous with 'refractory asthma', and the priority in patients labelled with refractory asthma is to confirm the diagnosis itself. Furthermore, the myriad presentations of a left atrial myxoma warrant its consideration whenever a patient presents with non-resolving respiratory complaints. In our case a more comprehensive cardiac examination including an echocardiography would have led to the correct diagnosis. This case- report should enlighten clinicians regarding other conditions masquerading as asthma.

\section{CASE PRESENTATION}

The patient initially presented with episodic wheeze of 3 years' duration that was refractory to treatment with inhaled steroids, oral bronchodilators and multiple courses of oral steroids prescribed by multiple primary care physicians. $\mathrm{He}$ also reported of dry cough and low grade intermittent fever of one month duration. He had no known history of allergy or bronchial asthma. There was no history of tuberculosis nor was there a history of contact with a patient known to be suffering from tuberculosis. The patient hailed from a middle-class background, and lived with his wife and two children. There was no history of pets at home.

\section{INVESTIGATIONS}

Initial laboratory investigations were normal except for a high erythrocyte sedimentation rate (ESR) of $110 \mathrm{~mm} / \mathrm{h}$. Pulmonary function testing revealed mild obstructive airway disease with bronchodilator reversibility. On arrival at our institution, a chest radiograph was taken and was normal. Two sputum samples were negative for acid fast bacilli by Ziehl-Neelsen staining. Bronchial Brush Cytology obtained via bronchoscopy was positive for acid-fast bacilli. As an evaluation for persistently high ESR, serum protein electrophoresis was carried out and was normal. Testing for antinuclear antibodies and antinuclear cytoplasmic antibodies was negative. High resolution CT revealed bilateral dependent ground glass opacities (figure 1). Two-dimensional echocardiography demonstrated a left atrial myxoma (figure 2) with mild mitral regurgitation, right atrial superior-inferior distance (in four-chamber view) of $2.3 \mathrm{~cm}$, right ventricular end-diastolic diameter

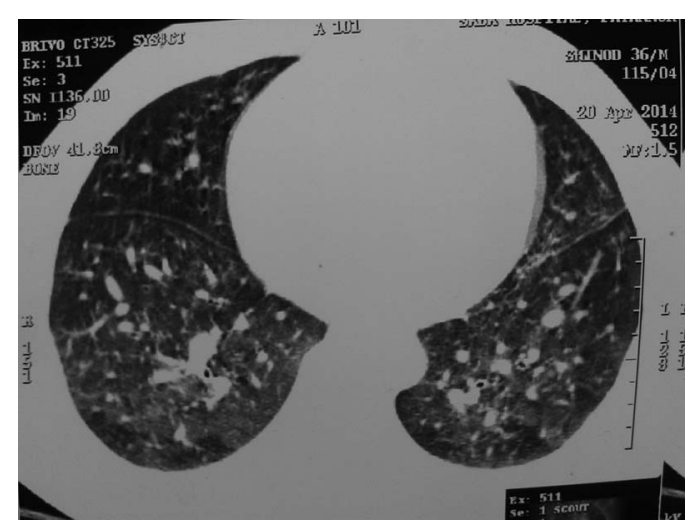

Figure 1 Contrast-enhanced CT of the chest showing bilateral dependent ground glass opacities. 


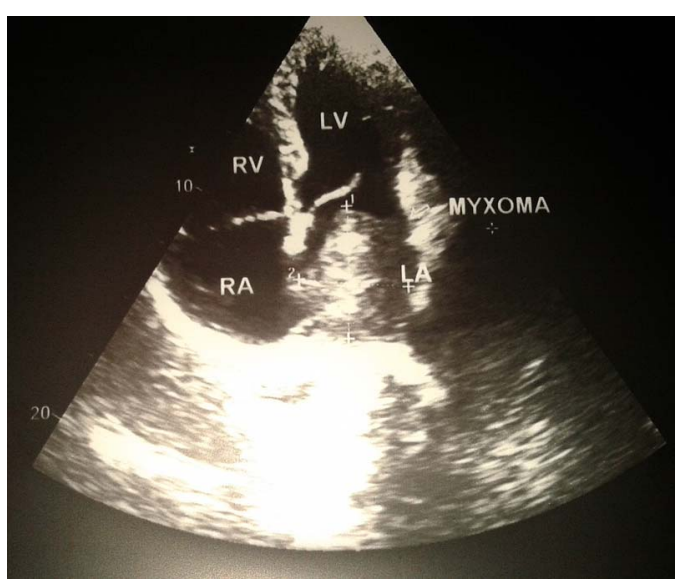

Figure 2 Two-dimensional echocardiography demonstrating a left atrial myxoma.

obtained by M-mode imaging was $1.2 \mathrm{~cm}$, RV systolic pressure was $18 \mathrm{~mm} \mathrm{Hg}$ and a TAPSE was $15 \mathrm{~mm}$.

\section{DIFFERENTIAL DIAGNOSIS}

\section{Bronchial asthma}

Hypersensitivity pneumonitis

The patient mentioned in our case report presented with a history of episodic wheeze and breathlessness of 3 years' duration with widespread polyphonic wheeze on examination. Pulmonary function testing revealed mild obstruction with bronchodilator reversibility. However, in spite of optimal treatment with inhaled bronchodilators, immunotherapy and steroids, the patient continued to be symptomatic. Hence, difficult to control bronchial asthma was considered as a differential diagnosis.

In view of high resolution CT of the chest demonstrating bilateral dependent ground glass opacities, and in view of the patient's clinical features, hypersensitivity pneumonitis was considered. However, there was no significant occupational history or pets at home, and no exposure to any other allergens.

Bronchial asthma and hypersensitivity pneumonitis were both later ruled out as two-dimensional echocardiography demonstrated a left-atrial myxoma that explained the patient's symptoms and signs.

\section{TREATMENT}

The cardiovascular surgery department was consulted for emergency surgery. The patient underwent successful surgical removal of the left atrial myxoma. No complications were reported.

\section{OUTCOME AND FOLLOW-UP}

The patient's symptoms completely resolved following surgery. He is asymptomatic on follow-up.

\section{DISCUSSION}

Although rare, atrial myxomas constitute the most common benign cardiac tumours with an incidence of up to 3 in 1000 patients. These are mostly located in the left atrium and uncommonly in the right atrium. Sudden death may occur in patients with atrial myxoma due to tumour embolisation or obstruction of blood flow at mitral or tricuspid valve.

Approximately 50\% of patients with myxomas may experience symptoms due to central or peripheral embolism or intracardiac obstruction, but $10 \%$ of patients may be completely asymptomatic. $^{4}$
The most common symptom associated with cardiac myxoma is congestive heart failure, followed by either systemic or pulmonary embolisation. ${ }^{5}$ Cases of right ${ }^{6}$ and left $^{7}$ pleural effusion suggesting heart failure ${ }^{8}$ or systemic disease ${ }^{9}$ were occasionally reported in the literature. Kanaan and Nuno ${ }^{10}$ reported a case of atrial myxoma presenting as asthma in a 15 -year-old adolescent. Laboratory abnormalities (eg, anaemia and elevations in the ESR, C reactive protein or globulin level) are present in $35 \%$ of patients, usually those with systemic symptoms. ${ }^{11}$

Two-dimensional echocardiography can generally be used to determine the location, size, shape, attachment and mobility of a myxoma, and is superior to one-dimensional echocardiography. ${ }^{12} 13$

Once a presumptive diagnosis of myxoma has been made on imaging studies, prompt resection is required because of the risk of embolisation or cardiovascular complications, including sudden death. The results of surgical resection are generally very good, with most series reporting an operative mortality rate under $5 \% .^{14}$

\section{Learning points}

- Refractory wheeze is common in clinical practice, and a complete evaluation is mandatory.

- It is important to consider cardiac causes for refractory wheeze such as left heart failure, mitral stenosis and left atrial myxoma.

- Left atrial myxoma most commonly presents as congestive heart failure but may rarely, as in our case, present with intractable wheeze masquerading as asthma.

- Two-dimensional echocardiography may be considered as an investigative tool in evaluation of refractory wheeze.

- It is important to diagnose left atrial myxoma as it is amenable to surgical resection.

Acknowledgements The authors would like to thank Dr Anand Venugopal, Medical Superintendent of KMC Hospital, Attavar and Jyothi Circle for granting us permission to access the case records. The authors would like to thank Dr Anand R, Professor and Head of the Department of Pulmonary Medicine, for his assistance throughout.

Contributors VA, NP and AK were involved with the write-up of the case.

Competing interests None.

Patient consent Obtained.

Provenance and peer review Not commissioned; externally peer reviewed.

\section{REFERENCES}

1 Boushey HA. Clinical diagnosis in adults. In: Barnes PJ, Grunstein MJ, Leff AR, Woolcock AJ, eds. Asthma. Baltimore, MD: Lippincott- Raven; 1997:1391-403.

2 Am J Respir Crit Care Med 2000;162:2341-51.

3 Irwin RS, Curley FJ, French CL. Difficult-to-control asthma: contributing factors and outcome of a systematic management protocol. Chest 1993;103:1662-9.

4 Reynen K. Cardiac myxomas. N Engl J Med 1995;333:1610-17.

5 Sabastine MS, Collucci WS, Schoen FS. Primary tumors of the heart. In: Braunwald E, Zipes DP, Libby P, et al. The heart disease. Philadelphia, Saunders Co., 2004:1741-55.

6 Strambu I, Iliesiu A, Cretul R, et al. Recurrent pleural effusion revealing a left atrial myxoma. Pneumologia 2002;51:54-8.

7 Andrews R, Pollock G. Atrial myxoma presenting as a pleural effusion and raised erythrocyte-sedimentation rate of unknown cause. J R Soc Med 1996;89:585-6.

8 Okazaki N, Munakata M, Yamaguti E, et al. A case of elderly (83-year-old) woman with possible left atrial myxoma. Kokyu To Junkan 1990;38:179-83.

9 Sanna A, Porcu M, Basciu M, et al. Left atrial myxoma simulating a systemic disease with pleural- pericardial effusion. Detection by two-dimensional echocardiography. Ann Ital Med Int 1989;4:44-7. 
10 Kanaan S, Nuno I. Atrial myxoma presenting as asthma in adolescent. Internet J Thorac Cardiovasc Surg 2006;8:2.

11 Aggarwal SK, Barik R, Sarma TC, et al. Clinical presentation and investigation findings in cardiac myxomas: new insights from the developing world. Am Heart J 2007;154:1102-7.

12 Köhler E, Böcker K, Leuner C, et al. Die diagnostischeWertigkeit von M-ModezweidimensionalerEchokardiographie und
ComputertomographieimVergleichzurHerzkatheteruntersuchungbei der ErkennungkardialerTumoren. Z Kardiol 1981;70:571-82.

13 DePace NL, Soulen RL, Kotler MN, et al. Two dimensional echocardiographic detection of intraatrial masses. Am J Cardiol 1981;48:954-60.

14 Rahmanian PB, Castillo JG, Sanz J, et al. Cardiac myxoma: preoperative diagnosis using a multimodal imaging approach and surgical outcome in a large contemporary series. Interact CardiovascThorac Surg 2007;6:479-83.

Copyright 2015 BMJ Publishing Group. All rights reserved. For permission to reuse any of this content visit http://group.bmj.com/group/rights-licensing/permissions.

BMJ Case Report Fellows may re-use this article for personal use and teaching without any further permission.

Become a Fellow of BMJ Case Reports today and you can:

- Submit as many cases as you like

- Enjoy fast sympathetic peer review and rapid publication of accepted articles

- Access all the published articles

- Re-use any of the published material for personal use and teaching without further permission

For information on Institutional Fellowships contact consortiasales@bmjgroup.com

Visit casereports.bmj.com for more articles like this and to become a Fellow 